Published in final edited form as:

Hear Res. 2008 April ; 238(1-2): 110-117.

\title{
Cochlear Implants and Brain Plasticity
}

\author{
James B. Fallon ${ }^{a, b}$, Dexter R. F. Irvine ${ }^{a, c}$, and Robert K. Shepherd ${ }^{a, b}$ \\ aBionic Ear Institute, 384-388 Albert Street, East Melbourne, VIC 3002, Australia \\ bDepartment of Otolaryngology, University of Melbourne, VIC 3002, Australia \\ cSchool of Psychology, Psychiatry, and Psychological Medicine, Faculty of Medicine, Nursing, and Health \\ Sciences, Monash University, VIC 3800, Australia
}

\begin{abstract}
Cochlear implants have been implanted in over 110,000 deaf adults and children worldwide and provide these patients with important auditory cues necessary for auditory awareness and speech perception via electrical stimulation of the auditory nerve (AN). In 1942 Woolsey \& Walzl presented the first report of cortical responses to localised electrical stimulation of different sectors of the AN in normal hearing cats, and established the cochleotopic organization of the projections to primary auditory cortex. Subsequently, individual cortical neurons in normal hearing animals have been shown to have well characterized input-output functions for electrical stimulation and decreasing response latencies with increasing stimulus strength. However, the central auditory system is not immutable, and has a remarkable capacity for plastic change, even into adulthood, as a result of changes in afferent input. This capacity for change is likely to contribute to the ongoing clinical improvements observed in speech perception for cochlear implant users. This review examines the evidence for changes of the response properties of neurons in, and consequently the functional organization of, the central auditory system produced by chronic, behaviourally relevant, electrical stimulation of the AN in profoundly deaf humans and animals.
\end{abstract}

\section{Keywords}

Electrical Stimulation; Auditory Cortex; Plasticity; Cochleotopy; Reorganisation

\section{Introduction}

Worldwide, over 110,000 deaf adult and children benefit from direct electrical stimulation of their AN via a cochlear implant. Implant recipients exhibit a wide range of speech perception skills with a range of factors identified as affecting clinical performance (Blamey et al., 1996). The level of performance of pre-linguistically deaf adults generally remains well below that of post-linguistically deaf adults (Busby et al., 1999; Busby et al., 1993; Eddington et al., 1978). It is remarkable that the best patients can exhibit near-normal open-set speech perception, at least in a quiet environment, given the abnormal (and in many ways impoverished) input provided by these devices. The importance of auditory experience in the clinical performance of cochlear implant users has been consistently emphasized (Blamey et al., 1996; Gantz et al., 1993; Rubinstein et al., 1999). Clearly, changes within the auditory

Corresponding Author: James B. Fallon, JFallon@ BionicEar.org, Tel: + 619929 8397, Fax: + 619663 1958, Bionic Ear Institute, 384-388 Albert Street, East Melbourne, VIC 3002, Australia.

Publisher's Disclaimer: This is a PDF file of an unedited manuscript that has been accepted for publication. As a service to our customers we are providing this early version of the manuscript. The manuscript will undergo copyediting, typesetting, and review of the resulting proof before it is published in its final citable form. Please note that during the production process errors may be discovered which could affect the content, and all legal disclaimers that apply to the journal pertain. 
system underlie some of the improvements in speech perception seen in implant patients with device use, although it has not been established whether the improvements are mediated by changes in auditory cortex per se.

The capacity for plasticity in the response properties of neurons in, and consequently the functional organization of, cortical and sub-cortical sensory structures was generally believed to be maximal within 'critical periods' during early development (Hensch, 2004). It was believed that changes in experience during these early periods - when neuronal pathways and connections were being formed - but not later in life could drive changes in sensory processing mechanisms. However, the capacity for plasticity in adult sensory systems, given appropriate patterns of behaviourally significant input, has more recently become generally accepted (for review see Kaas et al., 2001) and confirmed in the auditory system (for reviews see Irvine, 2007; Weinberger, 2007).

The effects of restrictions in output from the cochlea, in both immature and adult animals, on the tonotopic organisation (for review see Irvine et al., 2005) and the temporal processing ability (Bao et al., 2004), of the thalamo-cortical auditory system have been well characterised. Less well studied are the effects of chronic, behaviourally relevant, electrical stimulation of the AN - similar to that used in cochlear implants - on cochleotopic organisation and temporal processing.

Complicating the interpretation of plasticity in the auditory cortex produced by such stimulation is that there are many changes consequent on a sensorineural hearing loss that almost invariably precede the chronic stimulation (for review see Shepherd et al., 2006). These changes include: significant reduction in spiral ganglion neurons; de-myelination of residual spiral ganglion neuron soma and possibly part of their central processes; shrinkage of the perikaryon of neurons throughout the auditory pathway; and reduced spontaneous activity throughout the auditory pathway. As many of the changes associated with sensorineural hearing loss are 'down-stream' from the cortex in the auditory pathway, they affect the input, and the organization of that input, into the auditory cortex. This problem of interpretation due to down-stream changes is equally true of changes associated with chronic stimulation.

It is also important to note that not all changes in neural responsiveness and organization are necessarily plastic in nature, as some changes can be explained as passive consequences of the altered input. For example, the frequency tuning of AN fibres, and consequently of neurons throughout the auditory pathway, is immediately altered after destruction of the outer hair cells (Dallos et al., 1978). It is also not always a simple matter to distinguish between plastic and non-plastic changes (Calford, 2002; Irvine et al., 2005). However, we will define plasticity as involving some form of active or dynamic modification of neural properties resulting from the altered input.

This paper will review the evidence of plastic changes in the central auditory system resulting from chronic electrical stimulation of the AN, with an emphasis on behaviourally relevant stimulation. First, evidence from animal studies focussing on the response properties of neurons in, and the functional organization of, the primary auditory cortex (AI) will be reviewed. Second, electrophysiological and functional imaging studies of the auditory cortex in cochlear implant patients will be reviewed. Finally, the relationship between the reported changes in the auditory cortex and psychophysical studies of both pitch and speech perception will be discussed. 


\section{Animal Studies}

\section{Basic Response Properties}

Individual neurons within layer III/IV of AI of normal hearing (or acutely deafened) cats have well characterized input-output functions for electrical stimulation (Hartmann et al., 1997;

Popelar et al., 1995; Raggio et al., 2003; Schreiner et al., 1996). Neurons exhibit either monotonic $(\sim 55 \%)$ or non-monotonic input-output functions, with dynamic ranges of approximately $10 \mathrm{~dB}$, and minimum first spike latencies of around $8 \mathrm{~ms}$. Cortical field potentials exhibit both a short- $(<80 \mathrm{~ms})$ and long- $(\sim 150 \mathrm{~ms})$ latency response (Hartmann et al., 1997; Popelar et al., 1995). The long-latency responses are thought to be mediated by corticothalamic loops, and are proposed to be essential for short-term memory and processing in higher-order auditory centres (Klinke et al., 1999).

A short period of profound deafness ( 2 weeks) in an adult animal, results in a decrease in absolute threshold and an increase in dynamic range of neurons in AI (Raggio et al., 1999). Longer periods of deafness, including the early developmental period, result in little additional change to absolute threshold or dynamic range (Hartmann et al., 1997; Raggio et al., 1999). Cortical field potentials in congenitally deaf cats are reduced in size and exhibit only a middlelatency response, with no long-latency responses evident (Klinke et al., 1999; Klinke et al., 2001). There are no reports of changes in the temporal processing ability of AI neurons (i.e. changes in minimum latency, response jitter and maximum following rate). This is puzzling, given the occurrence of significant down-stream changes, including a decrease in the temporal processing ability of the inferior colliculus (IC), viz., increases in both the minimum latency and response jitter, and a decrease in the maximum following rate of individual neurons (Shepherd et al., 1999; Snyder et al., 1995). There are pronounced changes in current sinks (and therefore presumably synaptic currents) in different layers within AI, with a decrease in current sinks at long (>30ms) latencies in layers II, III and IV and a decrease in the deeper (infragranular) layers IV, V and VI at all latencies (Kral et al., 2000; Kral et al., 2001).

Evidence for cross-modal plasticity as a consequence of congenital deafness is equivocal. Although Rebillard et al. (1980) described invasion of AI by visual input, others have reported no evidence of visual responses in AI of congenitally deaf cats (Kral et al., 2003; Stewart et al., 1970).

Chronic, behaviourally relevant, electrical stimulation of the AN delivered from an early age results in significant changes in the response properties of neurons in AI compared to unstimulated deaf controls (Kral et al., 2006a). While there are no studies that have reported a systematic examination of stimulation-induced changes in single- or multi-unit threshold or dynamic range, cortical field potentials in stimulated animals are similar to those in normalhearing animals (Klinke et al., 2001). That is, there is an increase in the amplitude of the field potentials compared to deaf controls, and the potentials comprise both middle- and long-latency components. Chronic stimulation also results in more sustained single- and multi-unit activity than in unstimulated deaf controls (Klinke et al., 1999). A preliminary report indicates that chronic stimulation results in a increase in first spike latency and an increase in the maximum following rate of neurons in AI compared to deaf controls (Fallon et al., 2007b). It is difficult to determine if these changes can be interpreted as indicative of an increase or decrease in temporal processing: the increase in first spike latency suggests a decrease in temporal processing, whereas the increase in maximum following rate indicates improved temporal processing. In contrast, chronic stimulation (albeit not behaviourally relevant) results in a significant down-stream increase in temporal processing (decreased minimum latency and response jitter and increased maximum following frequency) in the IC (Snyder et al., 1995; Vollmer et al., 2005; Vollmer et al., 1999). Interestingly, the temporal processing of electrical stimuli in the IC of chronically stimulated animals is superior to that in normal hearing animals. 
Finally, chronic stimulation results in larger current source densities, resembling those in normal hearing animals (particularly in layers II \& III Klinke et al., 1999), although these are diminished with increasing delays in the initiation of the chronic stimulation.

There is a critical period for the reintroduction of auditory input into the deafened auditory system, during which changes can be driven simply by 'passive' experience. During this period neural activity and developmental cues may interact to effect the production of a range of neurotrophic factors important for dendritic growth and synaptic formation (for review see Kral et al., 2006b).

These results suggest that chronic, behaviourally relevant, electrical stimulation of the AN allows an experience-dependent maturation of the basic response properties of individual neurons within AI, albeit not exactly as would have occurred in a normal hearing animal.

\section{Cochleotopic Organisation}

In normal hearing (and acutely deafened) animals, AI exhibits a functional cochleotopic organization to restricted electrical stimulation of the AN (Woolsey et al., 1942). This cochleotopic organization of AI along a predominantly caudal-rostral axis is the corollary of the well studied tonotopic organization to acoustic stimulation. In normal hearing cats, one millimetre of shift along the basilar membrane corresponds to an approximately $1.82-\mathrm{mm}$ shift along the caudal-rostral axis (Raggio et al., 1999). Single biphasic pulses delivered at $6 \mathrm{~dB}$ above threshold result in the activation of a 2-mm wide dorso-ventral strip of AI (Raggio et al., 1999), which can be divided into dorsal and ventral zones, separated by a high threshold ridge. The area of cortex activated by a given stimulus changes during maturation, being largest one to two months after birth, and reaching adult-like levels around 4 months of age (Kral et al., 2005).

A short period of profound deafness ( 2 weeks) in an adult animal, results in a degradation of the normal cochleotopic organization (Raggio et al., 1999). Specifically, for a given stimulus, there is an increase in the area of cortex activated, primarily in the caudal-rostral extent. That is, rather than a stimulus $6 \mathrm{~dB}$ above threshold activating a 2-mm wide dorso-lateral strip, it now activates a 3- to 4-mm wide strip. However, cochleotopicity, as defined by the relative cortical locations of minimum threshold for each cochlear stimulating electrode, is maintained (i.e. a shift of one millimetre along the basilar membrane corresponds to an approximately 1.82 $\mathrm{mm}$ shift along the caudal-rostral axis of AI). The combined result of these two changes is an increase in overlap between adjacent basilar membrane representations. The effects of longer periods of deafness, including the early developmental period, appear to be influenced by aetiology. Specifically, congenitally deaf cats are reported to maintain a rudimentary mapping of cochlea to cortical location (Hartmann et al., 1997; Klinke et al., 1999; Kral et al., 2001; Kral et al., 2002). Congenitally deaf cats also demonstrate a delay in the maturation of cortical activation area, with cortical activation being largest approximately two months later than in normal-hearing animals, but achieving near normal adult levels (Kral et al., 2005). In contrast, neonatal deafening results not only in a similar spread of cortical activation as short-term deafness (i.e. a $6 \mathrm{~dB}$ supra-threshold stimulus activates a 3- to 4-mm wide dorso-lateral strip), but also in a complete or near-complete loss of the orderly mapping of cochlea location to cortical location (Fallon et al., 2007a; Raggio et al., 1999). Using optical imaging techniques, Dinse et al. (2003; 1997a) also reported a disintegration of the normal map, with the emergence of isolated islands or patches of activity in response to stimulation of a given electrode. The loss of cochleotopy in AI is in contrast to the electrophysiological evidence from lower centres, most notably the IC, in which a near-normal cochleotopic organisation is maintained even after extended periods of deafness (Leake et al., 2000; Moore et al., 2002; Shepherd et al., 1999; Snyder et al., 1990). 
Chronic, behaviourally relevant, electrical stimulation of a single sector of the AN delivered from an early age results in an expansion of the activated cortical area compared to unstimulated deaf controls (Klinke et al., 1999; Kral et al., 2001; Kral et al., 2002). The degree of expansion was related to the duration of electrical stimulation (Klinke et al., 2001; Kral et al., 2006a), with longer periods of electrical stimulation resulting in more cortical expansion, provided animals were implanted before approximately six months of age. There are few reports of the effects of chronic stimulation of multiple auditory nerve sectors on the cochlea-to-cortex mapping, but preliminary findings confirm an expansion in activated area superimposed on a relatively normal cochleotopy (Fallon et al., 2007a). The expansion in total activation area seen using electrophysiological techniques has also been reported in an optical imaging study (Dinse et al., 2003; Dinse et al., 1997a), but the expansion was of a very different sort. The large cortical territories activated by a single electrode were massively overlapping, such that there was "a profound reduction of representational selectivity", in contrast to the near-normal cochleotopy seen by Fallon et al. (2007a). The electrophysiologically described effects of chronic stimulation on the organisation of AI are similar in some respects to the down-stream changes, particularly those at the level of the IC. Specifically, chronic stimulation (albeit not behaviourally relevant) of a single restricted sector of the cochlear results in an expanded representation of that area in both immature (Snyder et al., 1990) and mature (Moore et al., 2002) animals. However, competing inputs, achieved by non-simultaneous stimulation of two distinct sectors of the cochlea, were shown to maintain - or even sharpen - the selectivity of representations of those sectors in the IC (Leake et al., 2000). In contrast, simultaneous stimulation of two cochlear sectors resulted in a marked expansion, fusing the representation of the two sectors (Leake et al., 2000). The effects of different stimulation regimes on the cochleotopic organisation of IC may partly explain the different effects of chronic stimulation in AI reported in the electrophysiological and optical imaging studies, as they also used different stimulation regimes. In particular, Dinse et al (2003) used a stimulation strategy in which all electrodes were stimulated near-simultaneously. It is also possible that the different effects reflect differences in the laminar location of the activity recorded by the two techniques: the electrophysiological data are predominantly from the middle cortical layers, and thus reflect thalamo-cortical input, whereas the optical imaging recordings predominantly reflect activity in the superficial cortical layers.

These results suggest that chronic, behaviourally relevant, electrical stimulation of the AN, capable of resulting in significant changes to the cochleotopic organisation of the auditory midbrain, can also effect the cochleotopic organisation of AI (see Figure 1). All studies have reported an expansion in the total activation area, but there are conflicting reports on the underlying cochlear to cortical mapping (see Figure 1), which may relate to the precise nature of the stimulation.

\section{Clinical Studies}

\section{Electrophysiology}

Evidence from clinical studies of the P1 evoked cortical potential indicates that there is a sensitive period, ending around 3.5 years of age, during which the human central auditory pathway is maximally plastic (Eggermont et al., 2003; Ponton et al., 2001; Ponton et al., 1996; Sharma et al., 2002). Children who receive effective cochlear stimulation within this period develop electrically evoked cortical potentials with latencies $(\sim 100 \mathrm{~ms})$ that reach those of aged-matched normal-hearing children within 6 months of the onset of stimulation (Sharma et al., 2005a). The recorded potentials suggest near-normal maturation of middle (IV \& deep III) cortical layers, but there continues to be altered maturation or input to the superficial (II, upper III) layers (Ponton et al., 2001). In contrast, genetically deaf children implanted after 7 years of age exhibit incomplete maturation of their electrically evoked cortical potentials, including latencies that are always longer than aged-matched controls, leading to the suggestion 
that the latency of this cortical evoked potential could be a useful diagnostic tool for determining the development of the auditory system (Sharma et al., 2006; Sharma et al., 2005 b). It is worth noting the P1 response is generated by both auditory thalamic and cortical sources (Sharma et al., 2005a).

\section{Imaging}

Modern imaging techniques for measuring brain activity in humans have also provided evidence for plasticity of the central auditory pathway following a profound hearing loss (Berthezene et al., 1997; Giraud et al., 2001; Hari et al., 1988; Herzog et al., 1991; Ito, 1993; Ito et al., 1993; Lazeyras et al., 2002; Nishimura et al., 2000; Okazawa et al., 1996; Pelizzone et al., 1986). Collectively, these studies report low levels of auditory cortical activity among profoundly deaf subjects - the longer the duration of deafness, the lower the level of activity recorded. Additionally, it appears that the auditory cortex can be activated by other sensory modalities, although the 'take over' of auditory areas appears to be limited to secondary auditory areas (supratemporal gyrus / perisylvian region) normally used for auditory processing and language (Hickok et al., 1997; Nishimura et al., 1999; Petitto et al., 2000; Sadato et al., 2004). There is however, at least one report that has described the recruitment of primary auditory cortex in the profoundly deaf for processing purely visual stimuli (Finney et al., 2001), although the extent of the take-over was limited to a small region of only the right, but not the left, primary auditory cortex.

Following cochlear implantation, metabolic activity in primary auditory cortex is reported to increase to near normal levels, with greater activity on the side contralateral to the implant (Lazeyras et al., 2002), and the magnitude of the increase appears to be correlated with the performance of the implant patient (Green et al., 2005; Lee et al., 2007). Interestingly, the activity in 'higher-order' auditory centres of prelingual deaf patients is reported to decrease with cochlear implant experience (Lee et al., 2001), and to be lower in these patients than in postlingual deaf implant patients (Naito et al., 1997). Clearly, it is auditory experience that drives the functional specialisation in auditory association areas (Giraud et al., 2001).

\section{Pitch and Speech Perception}

Normal electrode pitch perception - the ability to discriminate between stimulation on different electrodes and to rank the percepts in a manner consistent with a normal cochleotopic organization - is highly correlated with speech perception (Henry et al., 2000). Postlingually deaf implant patients exhibit normal pitch percepts (Cohen et al., 2001; Fu et al., 2002; Pfingst et al., 2001), with some patients even able to perceive 'virtual electrodes', created by pairing stimulating electrodes, between physical electrodes (Busby et al., 2005). An interesting recent observation is that in patients with some residual hearing, it is possible to create a mismatch between cochlear location and the perceived pitch (Reiss et al., 2007). Specifically, it is possible to assign any portion of the acoustic frequency spectrum as the driving signal for a particular intra-cochlear electrode. For some patients, particularly those with short intra-cochlear electrode arrays, their implants are programmed to deliver electrical stimulation derived from acoustic signals up to two octaves below those that would normally excite that cochlear region. After some years of device use, the electrode pitch percepts of these patients come to match the programmed frequencies, rather than those predicted on the basis of cochlear-position, suggesting top-down influences on the regions giving rise to the percept from areas in which knowledge of the frequency composition of the language is stored.

A universal finding is that word recognition scores in postlingually deaf implant patients are inversely correlated with the duration of deafness, and the ratio of duration of deafness to age of implantation has a negative impact on clinical performance (Blamey et al., 1996; Gantz et al., 1993; Govaerts et al., 2002; Kirk et al., 2002; Rubinstein et al., 1999; Sarant et al., 2001). 
The performance of postlingually deaf patients implanted later in life does not differ significantly from younger recipients (Leung et al., 2005; Tyler et al., 1996), emphasising the capacity of the adult auditory system to undergo change. Finally, patients with residual hearing typically have better speech perception scores than profoundly deaf patients (Gantz et al., 2005; Kiefer et al., 2005), reflecting - in part - their greater auditory processing experience.

Although prelingually deaf patients, implanted as young adults, improve with implant use, they typically exhibit poor levels of speech perception (Busby et al., 1999; Busby et al., 1993; Dowell, 2002; Eddington et al., 1978). Their temporal processing skills, as assessed by rate and gap detection tasks, are poor (Busby et al., 1999; Busby et al., 1993) and they do not exhibit normal electrode pitch percepts (Busby et al., 2000; Busby et al., 1992; Eddington et al., 1978; Tong et al., 1988). However, if implanted early, a majority of congenitally deaf children obtain open-set speech perception after 2-3 years of implant use at levels comparable to postlingually deaf adults (Dowell, 2002). As with postlingually deafened adults, auditory experience with cochlear implants is vital for good speech perception in children (Blamey et al., 2001; Dawson et al., 1992; Dowell, 2002; Fryauf-Bertschy et al., 1997; Osberger et al., 1991; Sarant et al., 2001; Waltzman et al., 1992). This is highlighted by children with a congenital hearing loss, who initially show poorer language development than children with an acquired hearing loss, but whose performance rapidly improves with device use (Dettman et al., 2007). Importantly, this improvement in communication skills begins to match that seen in normal development if the children receive a cochlear implant under 12 months of age (Dettman et al., 2007). Moreover, it is not surprising that family and educational environments emphasizing listening and speaking play a significant role in speech perception among paediatric cochlear implant subjects (Moog et al., 2003; Sarant et al., 2001).

A final interesting observation is that there is a positive correlation between low resting metabolic activity in the AI prior to cochlear implantation and post-implantation speech perception scores for the prelingual deaf (Lee et al., 2001; Lee et al., 2007). This suggests that while both the AI and other higher-order auditory centres are capable of plastic change, the best clinical outcomes for cochlear implant patients may in fact occur with the most immature auditory cortex, or the 'cleanest sheet'.

Collectively, studies of clinical performance in adult implant subjects consistently emphasize the negative influence of duration of deafness and the positive influence of auditory experience on speech perception, and suggest that there is a critical period within which auditory cortical structures important for language development must receive appropriate input. However, it is important to emphasize that these factors only account for $\sim 20 \%$ of the variance in the clinical data (Blamey et al., 1996); there remain other factors, as yet unidentified, that significantly contribute to clinical performance among implant subjects.

\section{Conclusion}

A growing body of functional imaging and psychophysical studies in humans and predominantly neurophysiological studies in animals is providing further evidence for plasticity in the central auditory pathway. It is clear that genetic cues are sufficient to generate a basic framework, with the development of at least a rudimentary pathway in the absence of any auditory experience, which is sufficient to provide both the temporal and spatial cues necessary for speech perception using a cochlear implant. However, auditory experience plays a key role in moulding the fine organisational structure of the central auditory system, and there is no doubt this plasticity contributes to the remarkable success of many cochlear implant subjects in achieving near-normal speech perception despite the abnormal (and in many ways impoverished) input provided by the prosthesis. 


\section{Acknowledgements}

The authors' research is supported by the National Institute of Deafness and Communication Disorders of the USA (N01-DC-3-1005).

\section{REFERENCES}

Bao S, Chang EF, Woods J, Merzenich MM. Temporal plasticity in the primary auditory cortex induced by operant perceptual learning. Nature Neuroscience 2004;7:974-981.

Berthezene Y, Truy E, Morgon A, Giard MH, Hermier M, Franconi JM, Froment JC. Auditory cortex activation in deaf subjects during cochlear electrical stimulation. Evaluation by functional magnetic resonance imaging. Invest Radiol 1997;32:297-301. [PubMed: 9140750]

Blamey P, Arndt P, Bergeron F, Bredberg G, Brimacombe J, Facer G, Larky J, Lindstrom B, Nedzelski J, Peterson A, Shipp D, Staller S, Whitford L. Factors affecting auditory performance of postlinguistically deaf adults using cochlear implants. Audiol Neurootol 1996;1:293-306. [PubMed: 9390810]

Blamey PJ, Sarant JZ, Paatsch LE, Barry JG, Bow CP, Wales RJ, Wright M, Psarros C, Rattigan K, Tooher R. Relationships among speech perception, production, language, hearing loss, and age in children with impaired hearing. J Speech Lang Hear Res 2001;44:264-285. [PubMed: 11324650]

Busby PA, Clark GM. Gap detection by early-deafened cochlear-implant subjects. J Acoust Soc Am 1999;105:1841-1852. [PubMed: 10089607]

Busby PA, Clark GM. Electrode discrimination by early-deafened subjects using the cochlear limited multiple-electrode cochlear implant. Ear Hear 2000;21:291-304. [PubMed: 10981605]

Busby PA, Plant KL. Dual electrode stimulation using the nucleus CI24RE cochlear implant: electrode impedance and pitch ranking studies. Ear and Hearing 2005;26:504-511. [PubMed: 16230899]

Busby PA, Tong YC, Clark GM. Psychophysical studies using a multiple-electrode cochlear implant in patients who were deafened early in life. Audiology 1992;31:95-111. [PubMed: 1610317]

Busby PA, Tong YC, Clark GM. Electrode position, repetition rate, and speech perception by early- and late-deafened cochlear implant patients. J Acoust Soc Am 1993;93:1058-1067. [PubMed: 8445117]

Calford MB. Dynamic representational plasticity in sensory cortex. Neuroscience 2002;111:709-738. [PubMed: 12031401]

Cohen LT, Saunders E, Clark GM. Psychophysics of a prototype peri-modiolar cochlear implant electrode array. Hear Res 2001;155:63-81. [PubMed: 11335077]

Dallos P, Harris D. Properties of auditory nerve responses in absence of outer hair cells. J Neurophysiol 1978;41:365-383. [PubMed: 650272]

Dawson PW, Blamey PJ, Rowland LC, Dettman SJ, Clark GM, Busby PA, Brown AM, Dowell RC, Rickards FW. Cochlear implants in children, adolescents, and prelinguistically deafened adults: speech perception. Journal of Speech and Hearing Research 1992;35:401-417. [PubMed: 1573879]

Dettman SJ, Pinder D, Briggs RJ, Dowell RC, Leigh JR. Communication development in children who receive the cochlear implant younger than 12 months: risks versus benefits. Ear Hear 2007;28:11S18S. [PubMed: 17496638]

Dinse HR, Godde B, Reuter G, Cords SM, Hilger T. Auditory cortical plasticity under operation: reorganization of auditory cortex induced by electric cochlear stimulation reveals adaptation to altered snesory input statistics. Speech Communication 2003;41:201-219.

Dinse HR, Reuter G, Cords SM, Godde B, Hilger T, Lenarz T. Optical imaging of cat auditory cortical organization after electrical stimulation of a multichannel cochlear implant: differential effects of acute and chronic stimulation. Am J Otol 1997a;18:S17-S18. [PubMed: 9391580]

Dinse HR, Godde B, Hilger T, Reuter G, Cords SM, Lenarz T, von Seelen W. Optical imaging of cat auditory cortex cochleotopic selectivity evoked by acute electrical stimulation of a multi-channel cochlear implant. Eur J Neurosci 1997b;9:113-119. [PubMed: 9042575]

Dowell RC, Dettman SJ, Blamey PJ, Barker EJ, Clark GM. Speech perception in children using cochlear implants: prediction of long-term outcomes. Cochlear Implants International 2002;3:1-18.

Eddington DK, Dobelle WH, Brackmann DE, Mladejovsky MG, Parkin JL. Auditory prostheses research with multiple channel intracochlear stimulation in man. Annals of Otology, Rhinology and Laryngology 1978;87:1-39. 
Eggermont JJ, Ponton CW. Auditory-evoked potential studies of cortical maturation in normal hearing and implanted children: correlations with changes in structure and speech perception. Acta Otolaryngol 2003;123:249-252. [PubMed: 12701751]

Fallon, JB.; Irvine, DRF.; Coco, A.; Donley, LM.; Millard, RE.; Shepherd, RK. Cochlear Implantation Influences The Cochleotopic Organisation Of The Primary Auditory Cortex In The Deafened Cat. In: Santi, PA., editor. Thirtieth Annual Mid Winter Research Meeting of the Association for Research in Otolaryngology. Vol. 30. Denver; 2007a. p. 219

Fallon, JB.; Irvine, DRF.; Coco, A.; Donley, LM.; Millard, RE.; Shepherd, RK. Cochlear Implantation Influences The Temporal Responsiveness Of The Primary Auditory Cortex In The Deafened Cat. In: Santi, PA., editor. Thirtieth Annual Mid Winter Research Meeting of the Association for Research in Otolaryngology. Vol. 30. Denver; 2007b. p. 160

Finney EM, Fine I, Dobkins KR. Visual stimuli activate auditory cortex in the deaf. Nat Neurosci 2001;4:1171-1173. [PubMed: 11704763]

Fryauf-Bertschy H, Tyler RS, Kelsay DM, Gantz BJ, Woodworth GG. Cochlear implant use by prelingually deafened children: the influences of age at implant and length of device use. J Speech Lang Hear Res 1997;40:183-199. [PubMed: 9113869]

Fu QJ, Shannon RV. Frequency mapping in cochlear implants. Ear Hear 2002;23:339-348. [PubMed: 12195176]

Gantz BJ, Turner C, Gfeller KE, Lowder MW. Preservation of hearing in cochlear implant surgery: advantages of combined electrical and acoustical speech processing. Laryngoscope 2005;115:796802. [PubMed: 15867642]

Gantz BJ, Woodworth GG, Knutson JF, Abbas PJ, Tyler RS. Multivariate predictors of audiological success with multichannel cochlear implants. Ann Otol Rhinol Laryngol 1993;102:909-916. [PubMed: 8285510]

Giraud AL, Truy E, Frackowiak R. Imaging plasticity in cochlear implant patients. Audiol Neurootol 2001;6:381-393. [PubMed: 11847465]

Govaerts PJ, De Beukelaer C, Daemers K, De Ceulaer G, Yperman M, Somers T, Schatteman I, Offeciers FE. Outcome of cochlear implantation at different ages from 0 to 6 years. Otol Neurotol 2002;23:885890. [PubMed: 12438851]

Green KM, Julyan PJ, Hastings DL, Ramsden RT. Auditory cortical activation and speech perception in cochlear implant users: effects of implant experience and duration of deafness. Hearing Research 2005;205:184-192. [PubMed: 15953527]

Hari R, Pelizzone M, Makela JP, Hallstrom J, Huttunen J, Knuutila J. Neuromagnetic responses from a deaf subject to stimuli presented through a multichannel cochlear prosthesis. Ear Hear 1988;9:148152. [PubMed: 3410178]

Hartmann R, Shepherd RK, Heid S, Klinke R. Response of the primary auditory cortex to electrical stimulation of the auditory nerve in the congenitally deaf white cat. Hear Res 1997;112:115-133. [PubMed: 9367234]

Henry BA, McKay CM, McDermott HJ, Clark GM. The relationship between speech perception and electrode discrimination in cochlear implantees. J Acoust Soc Am 2000;108:1269-1280. [PubMed: 11008827]

Hensch TK. Critical period regulation. Annu Rev Neurosci 2004;27:549-579. [PubMed: 15217343]

Herzog H, Lamprecht A, Kuhn A, Roden W, Vosteen KH, Feinendegen LE. Cortical activation in profoundly deaf patients during cochlear implant stimulation demonstrated by H2(15)O PET. J Comput Assist Tomogr 1991;15:369-375. [PubMed: 1851187]

Hickok G, Bellugi U, Klima ES. The basis of the neural organization for language: evidence from sign language aphasia. Rev Neurosci 1997;8:205-222. [PubMed: 9548233]

Irvine DR. Auditory cortical plasticity: Does it provide evidence for cognitive processing in the auditory cortex? Hear Res 2007;229:158-170. [PubMed: 17303356]

Irvine, DRF.; Wright, BA. Plasticity in Spectral Processing. In: Malmiercan, M.; Irvine, DRF., editors. Auditory Spectral Processing. San Diego: Elsevier Academic; 2005. p. 435-472.

Ito J. Auditory cortex activities in severely hearing-impaired and cochlear implant patients. Positron emission tomographic study. Adv Otorhinolaryngol 1993;48:29-34. [PubMed: 8273495] 
Ito J, Sakakibara J, Iwasaki Y, Yonekura Y. Positron emission tomography of auditory sensation in deaf patients and patients with cochlear implants. Ann Otol Rhinol Laryngol 1993;102:797-801. [PubMed: 8215101]

Kaas, JH.; Florence, SL. Reorganization of sensory and motor systems in adults mammals after injury. In: Kaas, JH., editor. The Mutable Brain. Amsterdam: Harwood Academic Publishers; 2001. p. 165-242.

Kiefer J, Pok M, Adunka O, Sturzebecher E, Baumgartner W, Schmidt M, Tillein J, Ye Q, Gstoettner W. Combined electric and acoustic stimulation of the auditory system: results of a clinical study. Audiol Neurootol 2005;10:134-144. [PubMed: 15724084]

Kirk KI, Miyamoto RT, Lento CL, Ying E, O’Neill T, Fears B. Effects of age at implantation in young children. Ann Otol Rhinol Laryngol 2002;189:69-73.

Klinke R, Kral A, Heid S, Tillein J, Hartmann R. Recruitment of the auditory cortex in congenitally deaf cats by long-term cochlear electrostimulation. Science 1999;285:1729-1733. [PubMed: 10481008]

Klinke R, Hartmann R, Heid S, Tillein J, Kral A. Plastic changes in the auditory cortex of congenitally deaf cats following cochlear implantation. Audiol Neurootol 2001;6:203-206. [PubMed: 11694728]

Kral A, Tillein J. Brain plasticity under cochlear implant stimulation. Adv Otorhinolaryngol 2006a; 64:89-108. [PubMed: 16891838]

Kral A, Schroder JH, Klinke R, Engel AK. Absence of cross-modal reorganization in the primary auditory cortex of congenitally deaf cats. Exp Brain Res 2003;153:605-613. [PubMed: 12961053]

Kral A, Hartmann R, Tillein J, Heid S, Klinke R. Congenital auditory deprivation reduces synaptic activity within the auditory cortex in a layer-specific manner. Cereb Cortex 2000;10:714-726. [PubMed: 10906318]

Kral A, Hartmann R, Tillein J, Heid S, Klinke R. Delayed maturation and sensitive periods in the auditory cortex. Audiol Neurootol 2001;6:346-362. [PubMed: 11847463]

Kral A, Hartmann R, Tillein J, Heid S, Klinke R. Hearing after congenital deafness: central auditory plasticity and sensory deprivation. Cereb Cortex 2002;12:797-807. [PubMed: 12122028]

Kral A, Tillein J, Heid S, Hartmann R, Klinke R. Postnatal cortical development in congenital auditory deprivation. Cereb Cortex 2005;15:552-562. [PubMed: 15319310]

Kral A, Tillein J, Heid S, Klinke R, Hartmann R. Cochlear implants: cortical plasticity in congenital deprivation. Prog Brain Res 2006b;157:283-313. [PubMed: 17167917]

Lazeyras F, Boex C, Sigrist A, Seghier ML, Cosendai G, Terrier F, Pelizzone M. Functional MRI of auditory cortex activated by multisite electrical stimulation of the cochlea. Neuroimage 2002;17:1010-1017. [PubMed: 12377174]

Leake PA, Snyder RL, Rebscher SJ, Moore CM, Vollmer M. Plasticity in central representations in the inferior colliculus induced by chronic single- vs. two-channel electrical stimulation by a cochlear implant after neonatal deafness. Hear Res 2000;147:221-241. [PubMed: 10962187]

Lee DS, Lee JS, Oh SH, Kim SK, Kim JW, Chung JK, Lee MC, Kim CS. Cross-modal plasticity and cochlear implants. Nature 2001;409:149-150. [PubMed: 11196628]

Lee HJ, Giraud AL, Kang E, Oh SH, Kang H, Kim CS, Lee DS. Cortical activity at rest predicts cochlear implantation outcome. Cereb Cortex 2007;17:909-917. [PubMed: 16731883]

Leung J, Wang NY, Yeagle JD, Chinnici J, Bowditch S, Francis HW, Niparko JK. Predictive models for cochlear implantation in elderly candidates. Arch Otolaryngol Head Neck Surg 2005;131:1049_ 1054. [PubMed: 16365217]

Moog JS, Geers AE. Epilogue: major findings, conclusions and implications for deaf education. Ear Hear 2003;24:121S-125S. [PubMed: 12612486]

Moore CM, Vollmer M, Leake PA, Snyder RL, Rebscher SJ. The effects of chronic intracochlear electrical stimulation on inferior colliculus spatial representation in adult deafened cats. Hearing Research 2002;164:82-96. [PubMed: 11950528]

Naito Y, Hirano S, Honjo I, Okazawa H, Ishizu K, Takahashi H, Fujiki N, Shiomi Y, Yonekura Y, Konishi J. Sound-induced activation of auditory cortices in cochlear implant users with post- and prelingual deafness demonstrated by positron emission tomography. Acta Otolaryngol 1997;117:490-496. [PubMed: 9288201]

Nishimura H, Hashikawa K, Doi K, Iwaki T, Watanabe Y, Kusuoka H, Nishimura T, Kubo T. Sign language 'heard' in the auditory cortex. Nature 1999;397:116. [PubMed: 9923672] 
Nishimura H, Doi K, Iwaki T, Hashikawa K, Oku N, Teratani T, Hasegawa T, Watanabe A, Nishimura T, Kubo T. Neural plasticity detected in short- and long-term cochlear implant users using PET. NeuroReport 2000;11:811-815. [PubMed: 10757525]

Okazawa H, Naito Y, Yonekura Y, Sadato N, Hirano S, Nishizawa S, Magata Y, Ishizu K, Tamaki N, Honjo I, Konishi J. Cochlear implant efficiency in pre- and postlingually deaf subjects. A study with H2(15)O and PET. Brain 1996;119:1297-1306. [PubMed: 8813292]

Osberger MJ, Todd SL, Berry SW, Robbins AM, Miyamoto RT. Effect of age at onset of deafness on children's speech perception abilities with a cochlear implant. Ann Otol Rhinol Laryngol 1991;100:883-888. [PubMed: 1746820]

Pelizzone M, Hari R, Makela J, Kaukoranta E, Montandon P. Activation of the auditory cortex by cochlear stimulation in a deaf patient. Neurosci Lett 1986;68:192-196. [PubMed: 3755811]

Petitto LA, Zatorre RJ, Gauna K, Nikelski EJ, Dostie D, Evans AC. Speech-like cerebral activity in profoundly deaf people processing signed languages: implications for the neural basis of human language. PNAS 2000;97:13961-13966. [PubMed: 11106400]

Pfingst BE, Franck KH, Xu L, Bauer EM, Zwolan TA. Effects of electrode configuration and place of stimulation on speech perception with cochlear prostheses. J Assoc Res Otolaryngol 2001;2:87-103. [PubMed: 11550528]

Ponton CW, Eggermont JJ. Of kittens and kids: altered cortical maturation following profound deafness and cochlear implant use. Audiol Neurootol 2001;6:363-380. [PubMed: 11847464]

Ponton CW, Don M, Eggermont JJ, Waring MD, Kwong B, Masuda A. Auditory system plasticity in children after long periods of complete deafness. Neuroreport 1996;8:61-65. [PubMed: 9051753]

Popelar J, Hartmann R, Syka J, Klinke R. Middle latency responses to acoustical and electrical stimulation of the cochlea in cats. Hear Res 1995;92:63-77. [PubMed: 8647747]

Raggio MW, Schreiner CE. Neuronal responses in cat primary auditory cortex to electrical cochlear stimulation. III. Activation patterns in short- and long-term deafness. J Neurophysiol 1999;82:35063526. [PubMed: 10601478]

Raggio MW, Schreiner CE. Neuronal responses in cat primary auditory cortex to electrical cochlear stimulation: IV. Activation pattern for sinusoidal stimulation. J Neurophysiol 2003;89:3190-3204. [PubMed: 12783954]

Rebillard G, Rebillard M, Pujol R. Factors affecting the recording of visual-evoked potentials from the deaf cat primary auditory cortex (AI). Brain Res 1980;188:252-254. [PubMed: 7370754]

Reiss LA, Turner CW, Erenberg SR, Gantz BJ. Changes in pitch with a cochlear implant over time. Journal of the Association for Research in Otolaryngology 2007;8:241-257. [PubMed: 17347777]

Rubinstein JT, Parkinson WS, Tyler RS, Gantz BJ. Residual speech recognition and cochlear implant performance: effects of implantation criteria. Am J Otol 1999;20:445-452. [PubMed: 10431885]

Sadato N, Okada T, Honda M, Matsuki KI, Yoshida M, Kashikura KI, Takei W, Sato T, Kochiyama T, Yonekura Y. Cross-modal integration and plastic changes revealed by lip movement, random-dot motion and sign languages in the hearing and deaf. Cereb Cortex. 2004

Sarant JZ, Blamey PJ, Dowell RC, Clark GM, Gibson WP. Variation in speech perception scores among children with cochlear implants. Ear Hear 2001;22:18-28. [PubMed: 11271973]

Schreiner CE, Raggio MW. Neuronal responses in cat primary auditory cortex to electrical cochlear stimulation. II. Repetition rate coding. J Neurophysiol 1996;75:1283-1300. [PubMed: 8867137]

Sharma A, Dorman MF. Central auditory development in children with cochlear implants: clinical implications. Adv Otorhinolaryngol 2006;64:66-88. [PubMed: 16891837]

Sharma A, Dorman MF, Spahr AJ. A sensitive period for the development of the central auditory system in children with cochlear implants: implications for age of implantation. Ear Hear 2002;23:532-539. [PubMed: 12476090]

Sharma A, Dorman MF, Kral A. The influence of a sensitive period on central auditory development in children with unilateral and bilateral cochlear implants. Hear Res 2005a;203:134-143. [PubMed: 15855038]

Sharma A, Martin K, Roland P, Bauer P, Sweeney MH, Gilley P, Dorman M. P1 latency as a biomarker for central auditory development in children with hearing impairment. J Am Acad Audiol 2005b; 16:564-573. [PubMed: 16295243] 
Shepherd RK, Baxi JH, Hardie NA. Response of inferior colliculus neurons to electrical stimulation of the auditory nerve in neonatally deafened cats. Journal of Neurophysiology 1999;82:1363-1380. [PubMed: 10482755]

Shepherd, RK.; Meltzer, NE.; Fallon, JB.; Ryugo, DK. Consequences of deafness and electrical stimulation on the peripheral and central auditory system. In: Waltzman, SB.; Roland, JT., editors. Cochlear Implants. 2nd Edition. Thieme; 2006. p. 25-39.

Snyder R, Leake P, Rebscher S, Beitel R. Temporal resolution of neurons in cat inferior colliculus to intracochlear electrical stimulation: effects of neonatal deafening and chronic stimulation. $\mathrm{J}$ Neurophysiol 1995;73:449-467. [PubMed: 7760111]

Snyder RL, Rebscher SJ, Cao KL, Leake PA, Kelly K. Chronic intracochlear electrical stimulation in the neonatally deafened cat. I: Expansion of central representation. Hearing Research 1990;50:7-33. [PubMed: 2076984]

Stewart DL, Starr A. Absence of visually influenced cells in auditory cortex of normal and congenitally deaf cats. Exp Neurol 1970;28:525-528. [PubMed: 5475921]

Tong YC, Busby PA, Clark GM. Perceptual studies on cochlear implant patients with early onset of profound hearing impairment prior to normal development of auditory, speech, and language skills. Journal of the Acoustical Society of America 1988;84:951-962. [PubMed: 3183213]

Tyler RS, Summerfield AQ. Cochlear implantation: relationships with research on auditory deprivation and acclimatization. Ear and Hearing 1996;17(3 Suppl):38S-50S. [PubMed: 8807275]

Vollmer M, Leake PA, Beitel RE, Rebscher SJ, Snyder RL. Degradation of temporal resolution in the auditory midbrain after prolonged deafness is reversed by electrical stimulation of the cochlea. Journal of Neurophysiology 2005;93:3339-3355. [PubMed: 15659529]

Vollmer M, Snyder RL, Leake PA, Beitel RE, Moore CM, Rebscher SJ. Temporal properties of chronic cochlear electrical stimulation determine temporal resolution of neurons in cat inferior colliculus. $\mathrm{J}$ Neurophysiol 1999;82:2883-2902. [PubMed: 10601427]

Waltzman SB, Cohen NL, Shapiro WH. Use of a multichannel cochlear implant in the congenitally and prelingually deaf population. Laryngoscope 1992;102:395-399. [PubMed: 1556888]

Weinberger NM. Auditory associative memory and representational plasticity in the primary auditory cortex. Hear Res. 2007

Woolsey C, Walzl E. Topical projection of nerve fibers from local regions of the cochlea to the cerebral cortex. Bulletin of Johns Hopkins Hospital 1942;71:315-344.

\section{Abbreviations}

AI, primary auditory cortex; AN, auditory nerve; IC, inferior colliculus. 
Normal

Hearing
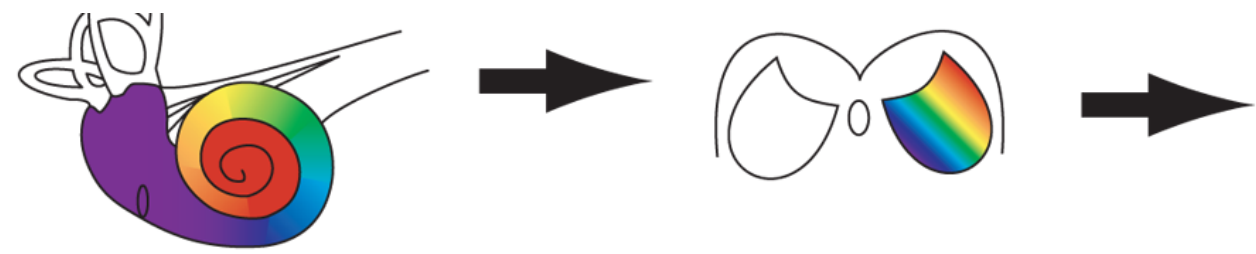

Congenitally Deaf
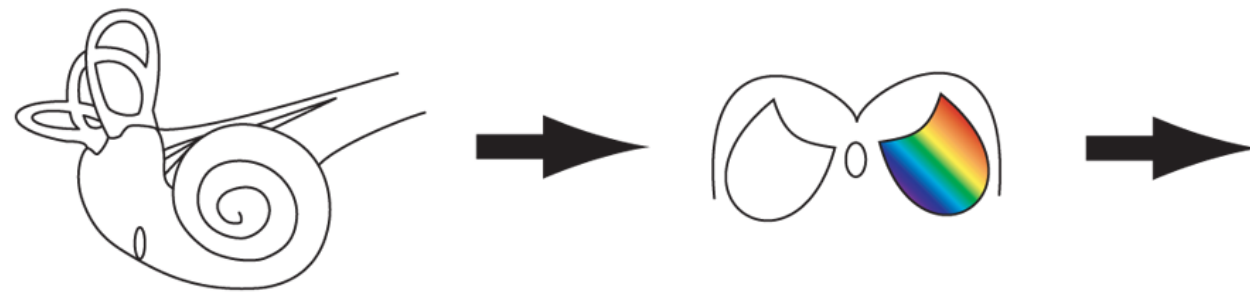

Neonatally

Deafened
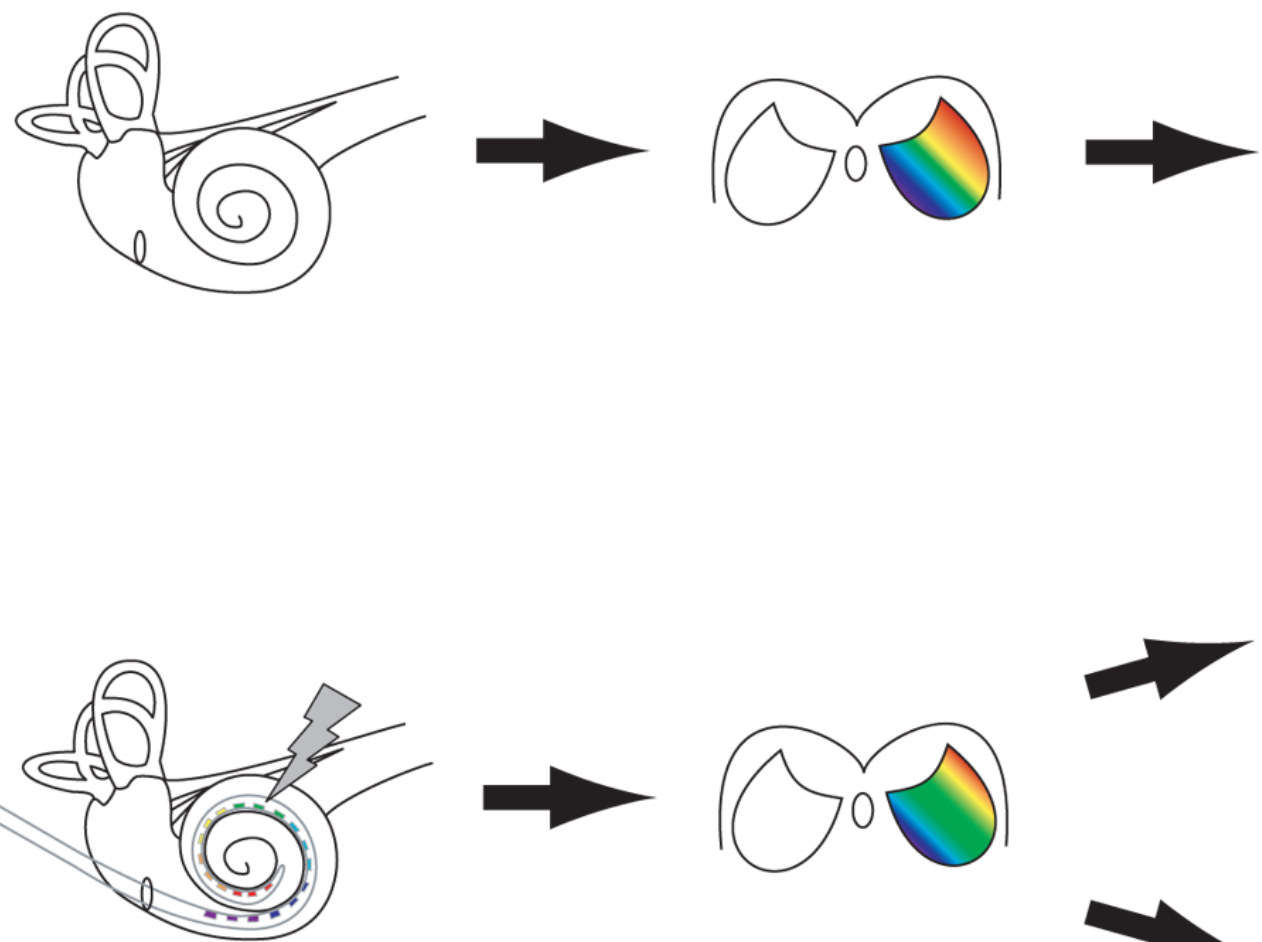

Neonatally

Deafened

Chronically

Stimulated
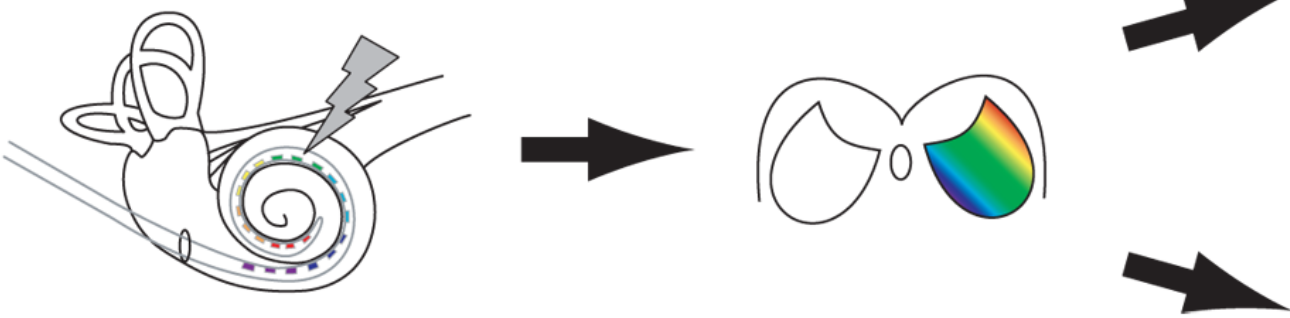

Figure 1.

Schematic representations of the cochleotopic organisation of the inferior colliculus (middle) and primary auditory cortex (right) in normal hearing animals (top row), congenitally deaf unstimulated animals (second row), neonatally deafened unstimulated animals (third row) and chronically-deaf chronically-stimulated animals (bottom row). The different results obtained with different recording techniques (optical imaging or electrophysiological) are illustrated. 